\title{
E-Auction Frauds - A Survey
}

\author{
VM.Noufidali \\ PG Scholar, \\ Department of CSE, \\ Karunya University, India.
}

\author{
Jobin S Thomas \\ PG Scholar, \\ Department of CSE, \\ Karunya University, India.
}

\author{
Felix Arokya Jose \\ Asst.Professor, \\ Department of CSE \\ Karunya University, India
}

\begin{abstract}
The current business arena shows unimaginable augmentation through applications providing all sorts of electronic customer services. One major proliferation was the overture of online auctions enabling the customer community to bid for and purchase large variety of goods. The nature of Internet auctions is high degree of anonymity, number of legal opportunities to buy and sell, and low costs for entry and exit, etc..., fraudsters can easily establish frauds in auction activities. Clear fact is that information asymmetry between sellers and buyers and lacking of immediately examining authenticity of the merchandise, the buyer can't verify the seller and the characteristics of the merchandise until after the transaction is completed. This paper classifies the different eauction frauds and its uncovering methods, doing a detailed analysis based on available bidding trends.
\end{abstract}

\section{Key words}

Detecting Techniques, Auction fraud, Data Mining, SNA, Reputation System.

\section{INDRODUCTION}

\subsection{Online Auction}

Auction is Latin word which means augment. Auctions have existed for centuries. Auction is a bid, a process of selling or buying and services offered take place. There are several different types of auctions and certain rules exist for each auction. There are variations for an auction which may include minimum price limit, maximum price limit and time limitations etc. Depending upon the auction method bidder can participate remotely or in person. Remote auction include participating through telephone, mail, and internet. Many economic transactions are conducted through auctions. Governments sell treasury bills, foreign exchange, publicly owned companies, mineral rights, and more recently airwave spectrum rights via auctions. Art work, antiques, cars, and houses are also sold by auctions. Government contracts are awarded by procurement auctions, which are also used by firm to buy inputs or to subcontract work. There are four commonly used and studied forms of auctions, it's are given below [21].

- Ascending Order Bidding

- Descending Order Bidding

- $\quad$ First-Price Preserved Bidding

- $\quad$ Second-Price Preserved Bidding
These forms are classified according to the price and order of attempt. To pick from the available bidding styles, ascending order variant is the simplest and primitive approach. The descriptions of different auction forms are tabulated in Table I.

\subsection{Online Auction Fraud}

The vast profits of online auction also attract the attention of criminals who use fraud to cash in on the profitable online trading market. According to annual reports of the Internet Complaint Center, online auction fraud ranks as one of the top serious internet crimes in recent years, the reports shows an increasing of internet crimes respect previous year, in 2001 the centre inward over 300,000 complaints with an increase of 3.4-percent and the total loss was $\$ 485.3$ million. Yearly comparison of complaints statistics is in fig 1 [17]. Most online auction houses realize that fraud corrodes not only their trustworthiness but also the prosperity of the entire market. For instance, multiple online identities are easy to create and a fraudster could use his many accounts to execute complicated schemes, while camouflaging his malicious target and escaping traditional detection methods that simply examine individual identities [17]. As more and more inexperienced traders become targeted victims, they begin to distrust the market, resulting in fewer buyers and fewer sellers [19]. To help promote trust in the online market, auction houses developed reputation systems to assist users in evaluating potential trading partners.

Table 1 Auction Forms Description

\begin{tabular}{|l|l|}
\hline \multicolumn{2}{|c|}{ Different forms of Auctions } \\
\hline Auction Forms & Description \\
\hline Ascending Order Bidding & $\begin{array}{l}\text { Cost is updated until and } \\
\text { unless a customer (bidder) } \\
\text { persists. }\end{array}$ \\
\hline Descending Order Bidding & $\begin{array}{l}\text { The auctioneer starts at a very } \\
\text { high price and lowers it } \\
\text { continuously until someone } \\
\text { accepts the currently } \\
\text { announced price. }\end{array}$ \\
\hline First-Price Preserved Bid & $\begin{array}{l}\text { Each bidder submits her bid in } \\
\text { a sealed envelope without } \\
\text { seeing other's bids, and the } \\
\text { object is sold to the highest } \\
\text { bidder at her bid. }\end{array}$ \\
\hline $\begin{array}{l}\text { Second-Price Preserved } \\
\text { Bidding }\end{array}$ & $\begin{array}{l}\text { Bidders submit their bids in a } \\
\text { sealed envelope; the highest } \\
\text { bidder wins but pays the } \\
\text { second highest bid. }\end{array}$ \\
\hline
\end{tabular}




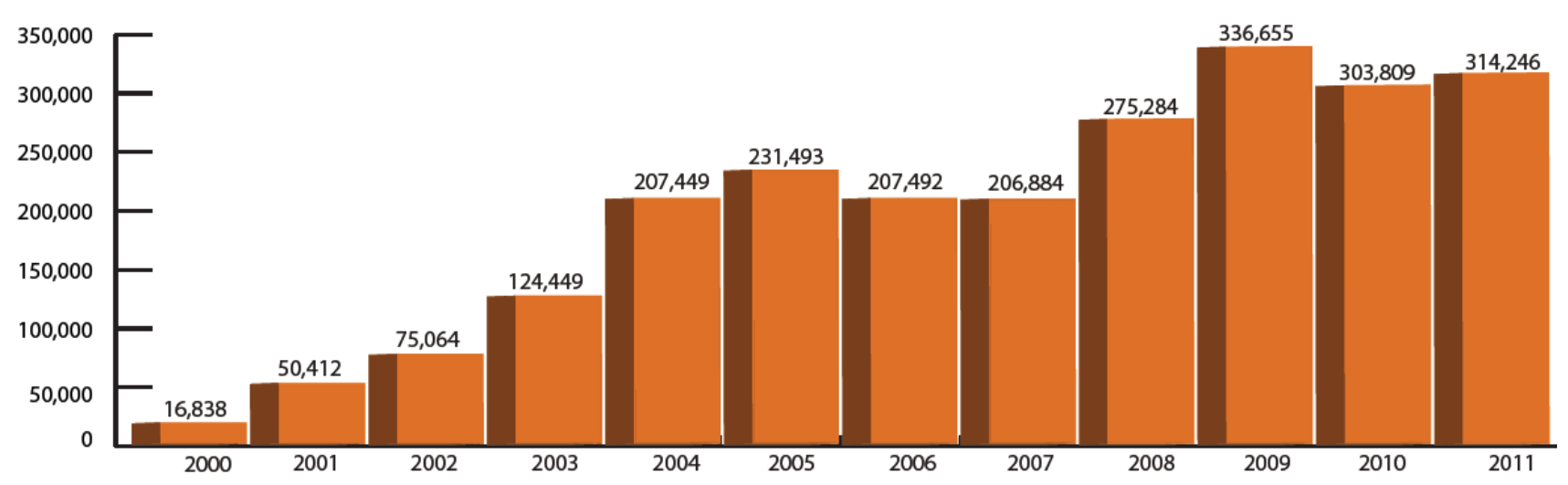

Fig 1 Yearly Complaints Evaluation

\section{AUCTION FRAUD CLASSIFICATION}

Here we concentrate on the category of online auction frauds. To recognize online auction fraud, it is suitable to first classify the various types of online auction fraud according to the two time periods in which the fraudulent behaviour can take place, it is offline behaviour and online behaviour. In the auction frauds misrepresentation of items, selling of black market goods and triangulation usually happen before the auctions start and non-delivery of goods and fee stacking happen after auctions close, so here classify

them as offline behaviour fraud. So the offline behaviour frauds that can often easily be noticed by buyers and sellers, examination of such frauds relies more on real-world evidence than on online prevention and detection mechanisms. However, online behaviour frauds happens while transactions are in progress, thus it may occur without leaving direct bodily evidence, and worst of all may not even be noticed by the victims. Types of auction frauds are classified in the fig 2.1. In fig 2.1 the auction frauds are classified two ways, one is offline behaviour and next is online behaviour. Here offline

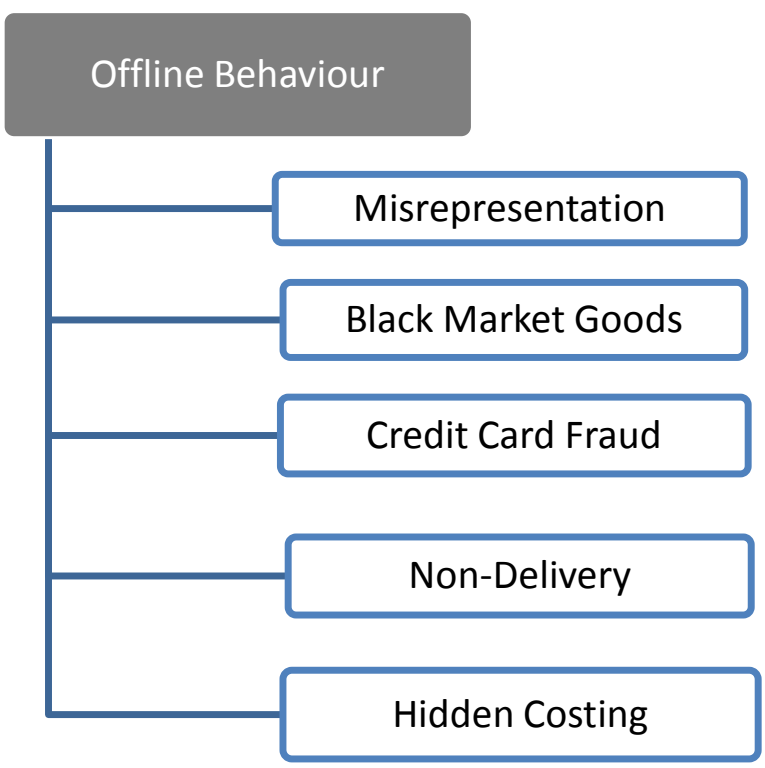

auction frauds are classified in five types it happened before the auction start or after the auction close. Online auction frauds are classified five types, it happens while transactions are in progress. The description of fraud types are tabulated in Table 2. [20]

In Online behaviours the shill bidding is very dangerous. Shill bidding refers to fraud done by the seller in a way that seller entered customers bid high amounts, eventually raising the commodity price and the normal bidders get cheated. Next fraud variant is coined as dummy biddings. As the name suggests, dummies persist in the bidding community and this anonymity triggers a very critical online auction fraud practice. The practice includes fooling legitimate bidders to believe the virtually rationalized auction fraud which can also be used to make the seller to cut down prices. In Bid Shading, the bidder could use an unfair method to know the highest bid before the bids are disclosed. The next line of attack is several bidding. As the name suggests, the buyers register several aliases and use them to place multiple bids for the same item. And finally bidding rings refers to collusive auction fraud behaviours conducted by several bidders.

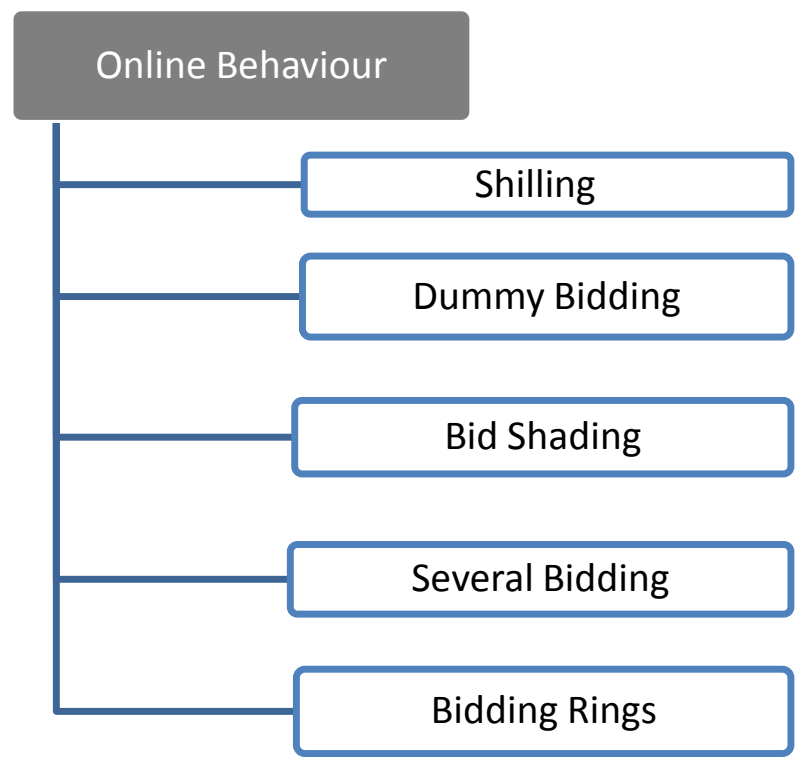

Fig 2.1 Auction frauds classification 
Table 2 Auction Frauds Description

\begin{tabular}{|c|c|c|c|}
\hline \multicolumn{2}{|c|}{ Offline behaviour } & \multicolumn{2}{|r|}{ Online behaviour } \\
\hline Fraud type & Description & Fraud type & Description \\
\hline Misrepresenting & $\begin{array}{l}\text { Seller purposely describes an item } \\
\text { incorrectly. }\end{array}$ & Shilling & $\begin{array}{l}\text { Seller bids on own auction to drive up } \\
\text { its price. }\end{array}$ \\
\hline Black Market Goods & $\begin{array}{l}\text { The unlawful marketing (selling } \\
\text { and purchasing) of boarded or tax } \\
\text { evaded goods violating government } \\
\text { norms. }\end{array}$ & Dummy Bidding & $\begin{array}{l}\text { Two bidders collude on an auction: One } \\
\text { makes a low bid, while the second } \\
\text { makes an Inflated bid. Seconds before } \\
\text { the auction ends, the high bidder } \\
\text { withdraws. }\end{array}$ \\
\hline Credit Card Fraud & $\begin{array}{l}\text { Using Stolen credit card to pay } \\
\text { purchased amount. }\end{array}$ & Bid Shading & $\begin{array}{l}\text { bidder could use an unfair method to } \\
\text { know the highest bid before the bids are } \\
\text { disclosed }\end{array}$ \\
\hline Non-Delivery & $\begin{array}{l}\text { Seller never sends the goods after } \\
\text { the auction complete. }\end{array}$ & Several Bidding & $\begin{array}{l}\text { The buyers register several aliases and } \\
\text { use them to place multiple bids for the } \\
\text { same item. }\end{array}$ \\
\hline Hidden Costing & $\begin{array}{l}\text { Seller adds hidden costs such as } \\
\text { handling charges to the item after } \\
\text { the auction ends. }\end{array}$ & Bidding Rings & $\begin{array}{l}\text { It refers to collusive auction fraud } \\
\text { behaviours conducted by several } \\
\text { bidders. }\end{array}$ \\
\hline
\end{tabular}

\section{FRAUD DETECTION APPROACHES}

\subsection{Feedback Based Reputation Systems}

Feedback based reputation system is a one of the simplest fraud detection system. In these systems help buyers decide whether to purchase a product based on a feedback score. After the completion of auction, both the seller and the buyer can put down ratings and feedback comments on the other party. These comments and feedback build up in the trader's transaction history, of which the feedback score is one part. So this type of reputation system is simple and easy to understand. It uses positive, neutral, and negative to denote the level of fulfilment for a trade. Analyse the reputation system capacity of finding fraudulent behaviour; it has major drawbacks. Most online auction houses agree to passive approaches to the coordination of reputation systems and management policies that could address fraudulent schemes. Though, if users had more proactive approaches, such as an automatic fraud detector, online auctioning could be safer. The reputation systems development, the most auction houses are used simple method. The auction houses used the method of marking rates, after a transaction is completed, the traders can only be rated on a positive, neutral and negative scale. The both buyer and seller want to be a good name, so they try to increase the positive feedback, so some of them try to increase their reputation with ambiguous means. Crook could attract buyers by fabricating transaction records that inflate their feedback scores in order to hide their malicious intent. In online auction the buyer using the common fraudulent trick is to first make several small businesses in order earn more positive feedback rating score, but then cheat later on the first expensive product. Another common type fraud is using multiple identities in online auctions. In this type a fraudster first creates multiple identities, dividing them into two groups, fraudsters and legitimate. Then, the fraudsters use the legitimate to artificially boost their reputations by leaving positive ratings. In adding together to the positive rating management, the negative feedback can be prejudiced by fraudulent traders as well. Checking the history of buyer and seller they be worthy of negative feedback ratings intimidate their trading partners into leaving positive ratings, regardless of the actual experience. Here we propose a method to increase the confidentiality of reputation system is using the combination of statistical modelling and automatic anomaly detection based reputation system. It is the best way to improve the quality of reputation system $[5,8]$.

\subsection{Data Mining Based Fraud Detection}

Data mining the other name is knowledge discovery is a powerful computer-assisted process designed to analyze and take out useful information from historical data [1]. It allows users to analyze data from different magnitude or perspectives in order to uncover consistent patterns, anomalies and systematic correlations between data elements. The data mining technique used in different areas, the ultimate objective of data mining is to predict future behaviours and trends based on the discovered patterns and association rules. In the area of research most of the researchers have adopted data mining methods to detect shill associations and suspicious patterns [9]. The main steps for implementing this approach for fraud detection within a business organization are [10]. Analyze the fraud objectives and the possible 
fraudsters, in order to converting them into data mining objectives.

- Data collection and understanding.

- Data cleaning and preparation for the algorithms.

- Experiment design.

- Evaluation results in order to review the process. Data mining approaches, like reputation approaches, also require analyzing huge amounts of historical data, and therefore take a very long time to get results. Using data mining approaches do have the advantage of accuracy compared to reputation systems. [21]

\subsection{Social Network Analysis Based Fraud Detection}

Social network analysis is a set of research procedures for identifying structures in systems based on the relations among actors [7]. Grounded in graph and system theories, this approach has proven to be a powerful tool for studying networks in physical and social worlds, including on the web. In the recent years social network approach has been increasingly applied in fraud detection in internet. With the development of web technologies, there is an increasingly greater amount of interaction by people while on the Internet. Social Networks bring in a multi-disciplinary approach to solve problems in this domain. It gives new ideas to old problems and gives a new way of looking at them [13]. Social Network Analysis focuses on using quantitative measurement to study the contact among the members to profile the structure of the neighbourhood and its members. It has been developed and practiced in the domain of social studies for decades. Now a day's SNA methods are used among social scientists to investigate the dynamics of a social group.
Focuses have been put on advice network, trust network, and communication network. The basic components of SNA study is the node, as the source of action, and the connection or link, as the relationship developed among nodes. The nodes can be individuals, organizations, or communities [11, 12]. And the links can be one or multiple type of relations or characteristics among the actors for understanding the effects to the social structure to individual members as well as the community as a whole [13].

Network analysis is most effective when combined with other methods in developing theory. Identifying clusters and blocks, or observing patterns in graphic models are technique that enhances descriptions of member's behaviour and the systems within which the behaviour takes place. Finally, testing hypotheses about networks requires comparable data from many networks, or large networks with many subgroups so that the output from network analysis may be imported into standard data files for conventional quantitative analysis. [15]

SNA also come with some limitation regarding data and data processing, proactively fighting fraud and regulatory barriers, because the data observation time and investigation time is very high in social network analysis. Data remodelling is required so that the effectiveness of SNA does not deteriorate as the volume of data observed increases. Data storage areas like SQL though quite efficient because significant overheads due to the joint operation performed on extremely large datasets that could increase investigation time. Transactional systems data needs to be remodelled to avoid disambiguation, and improve data consolidation and aggregation for enhanced data availability [14].The Table 3 compared the different fraud detection approaches.

Table 3 Comparison of Fraud Detection Techniques

\begin{tabular}{|l|l|l|l|}
\hline \multicolumn{4}{|c|}{ Comparison of Fraud Detection Techniques } \\
\hline Techniques & Reputation system & Data mining Based system & Social network analysis \\
\hline Real Time Support & No & No & Yes \\
\hline Data Type & Historical Data needed & Historical Data needed & Node Based Data Needed \\
\hline Merits & Easiest accessible tool & $\begin{array}{l}\text { powerful computer-assisted } \\
\text { process }\end{array}$ & $\begin{array}{l}\text { powerful tool for studying networks } \\
\text { in physical and social worlds }\end{array}$ \\
\hline Demerits & $\begin{array}{l}\text { Fail to provide users } \\
\text { trustworthy and accurate } \\
\text { information }\end{array}$ & $\begin{array}{l}\text { Analyzing huge amounts of } \\
\text { historical data }\end{array}$ & Large datasets Needed \\
\hline Efficiency & Low & High & High \\
\hline Time Required & Less time required & More time required & More time required \\
\hline Accuracy & Low & High & High \\
\hline
\end{tabular}

\section{CONCLUSION}

Analysis of the current trend of internet usage shows an exponential proliferation in the online auction sites and their users. An equal and opposite downside to this online practice is the fraud happening alongside. All these transgression remained to be veiled till recent years and now the real time reports highlight stumbling numbers of online frauds. Thus for the reason, we survey and analyze various fraud uncovering methods to find their knock in delivering performance in real time scenarios by unveiling these awful fraud practice

\section{ACKNOWLEDGEMENT}

We thank to all anonymous referees of the careful review of this paper and the suggestions for improvement they provided. We also thank Mr. Felix Arokya Jose for his help, which significantly improved the preparation of this paper. This work was support in part by Karunya university M.Tech thesis submission award 


\section{REFERENCES}

[1] Michel J.A Berry Gordon S.Linoff,"Data Mining Techniques" Second edition WILEY Publication.

[2] P. Resnick, K. Kuwabara, R. Zeckhauser, and E. Friedman."Reputation systems" Communications of the ACM, 43(12),2000.

[3] J. Han and M. Kamber, "Data Mining: Concepts and Techniques", Morgan Kaufmann Publishers, 2001.

[4] P. Resnick and R. Zeckhauser. "Trust among strangers in Internet transactions: Empirical analysis of eBay's reputation system".

[5] In M. R. Baye, editor, The Economics of the Internet and E-Commerce, volume 11 of Advances in Applied Microeconomics. Elsevier Science, Amsterdam, Netherlands, 2002.

[6] Pereira, A., Lago, A Maranzato, R. and Neubert, M. "Fraud detection in reputation systems in e-markets using logistic regression." In Proceedings of the 2010 ACM Symposium on Applied Computing, Sierre, Switzerland, March 22-26, 2010, ACM Press, New York, NY, 2010, 14-26.

[7] Wang, J., and Chiu, C. Q. "Detecting online auction inflated-reputation behaviours using social network analysis". In Proceedings of North American Association for Computational Social and Organizational Science 2005, Notre Dame, Indiana, June 26-28, 2005.

[8] Rubin, S., Christodorescu, M., Ganapathy, V., Giffin, J. T., Louis Kruger, L., Wang, H.,and Kidd, N. "An auctioning reputation system based on anomaly". In Proceedings of the 12th ACM Conference on Computer and Communications Security, Alexandria, VA, November 7-10, 2005, ACM Press, New York, NY, 2005.

[9] Pandit, S., Chau, D. H., Wang, S., and Faloutsos, C. NetProbe: "A fast and scalable system for fraud detection in online auction networks". In Proceedings of the 16th international Conference on the World Wide Web, Banff, Canada, May 8-12, 2007,201-210.
[10] Shai Rubin, Mihai,Christodorescu,Vinod Ganapathy, Jonathon T. Giffin Louis Kruger Hao Wang:"Auctioning Reputation System Based on Anomaly Detection" Computer Sciences Department University of Wisconsin, Madison

[11] Roberto Marmo "Data Mining for Fraud Detection System" University of Pavia, Italy.

[12] Kenneth A. Frank "Mapping interactions within and between cohesive subgroups" Michigan State University, Department of Counselling, Educational Psychology and Special Education, East Lansing, M148824-1034, USA

[13] Borgatti, P. "What Is Social Network Analysis?" 1998.1998 Social Networks Conference in Barcelona, $5-21$

[14] Freeman, L.C. "Centrality in Social Network: I. Conceptual Clarification," Social Networks (1) 1979.

[15] H. Goldberg and R. Wong (1998). "Restructuring Transactional Data for Link Analysis in the FinCEN AI System.”AAAI Technical Report FS-9801,www.aaai.org.

[16] NW3C. National white collar crime and the Federal Bureau Investigation: 2009 Internet crime report January 1-December

[17] IC3 annual report about frauds www.ic3.gov/media/annualreport/2011_IC3Report.pdf.

[18] Chau, P. "Catching bad guys with graph mining". XRDS: Crossroads, The ACM Magazine for Students $17,3,2011$.

[19] Gavish, B., and Tucci, C. "Reducing Internet auction fraud". Communications of the ACM, 51, 5, 2008, 8997.

[20] eBay Inc. First quarter 2005 financial results, April 2005.

[21] Fei Donga, Sol M. Shatza and Haiping Xub "Combating Online In-Auction Fraud: Clues, Techniques andChallenges"

[22] Online auction deal or steal http://www.scambusters.org/Scambusters43.html 